\title{
Application of Friction Pendulum Damper in Braced Frames and Its Effects on Structural Response
}

\author{
S. M. Zahrai, M. S. Bozorgvar, and M. H. Bozorgvar
}

\begin{abstract}
In this paper Friction Pendulum Damper (FPD), as an innovative friction damper, has been studied, evaluated and compared with Pall friction damper. At first FPD is introduced and then its modeling and effect on seismic behavior of braced frame structures are studied. To evaluate the effects of radius of curvature and slip-load on structural responses, nonlinear time history analysis of two, three and eight storey steel braced frames with FPD dampers have been conducted under two different earthquakes. Finally, the behavior of steel braced frames equipped with FPD and Pall friction damper are compared. The results show that while some members are damaged in frames without dampers, the FPD and Pall friction damper have dissipated a lot of energy, so that no damage is observed in structural members. Increasing the radius of curvature, leads to more maximum roof displacement but decreases both base shear and roof acceleration. However, increasing the slip load leads to less displacement while base shear and roof acceleration increase. Within the optimum slip load the maximum roof displacement, base shear and acceleration under two earthquakes are approximately reduced $25 \%, 60 \%$ and $25 \%$ respectively. The results show that the FPD is more effective than Pall friction damper, so that FPD can reduces the maximum roof displacement $15 \%$ more than Pall friction damper. However, the base shear is increased about $20 \%$.
\end{abstract}

Index Terms-Braced frame, friction pendulum damper (FPD), friction pendulum system (FPS), optimum slip load.

\section{INTRODUCTION}

In the conventional methods, structures resist against earthquakes via stiffness, ductility and dissipation of energy. Dissipated energy is minor in elastic range due to low damping in structures. The most dissipated energy develops during strong earthquakes after the elastic range behavior. The potential of inelastic displacement makes these structures to be stable. These inelastic displacements cause formation of plastic hinges at some points of structures. As it is known, plastic hinges cause ductility and dissipation of energy to increase. Ultimately, a lot of earthquake energy is dissipated due to local damages in lateral resistant system of structure [1].

Nowadays, another way has been concerned in the world in order to reduce earthquake effects with regard to how energy is distributed in structures. During an earthquake, a lot of energy is imposed to the structure. This energy enters the structure in both kinematic and potential forms absorbed or

Manuscript received January 12, 2014; revised March 12, 2014.

S. Mehdi Zahrai is with Center of Excellence for Engineering and Management of Civil Infrastructures School of Civil Engineering, Faculty of Engineering. The Univ. of Tehran, Iran (e-mail: mzahrai@ut.ac.ir)

M. S. Bozorgvar and M. H. Bozorgvar are with Structural Engineering, Islamic Azad University of Arak, Iran (e-mail masoud_bozorgvar@yahoo.com,msbs_302@yahoo.com) dissipated to some degrees. As it is known, structural vibrations will approach infinity without damping, but there is always damping in structures because of structural properties. Also, it is possible to develop efficiency of structure by adding dampers [2].

As mentioned, Structures can dissipate a lot of energy during earthquake via ductility, but the incidence of much ductility will be accompanied by formation of plastic hinges at some elements of structure [3]. Energy dissipation systems in buildings cause reduction of damage in structural elements during earthquake and as a result they prevent buildings from demolishing. Generally, Structural protective systems can be divided into three groups of active, semi-active and passive systems (seismic isolation is included in the passive systems). Structural protective systems have been shown in Fig. 1 [4], [5].

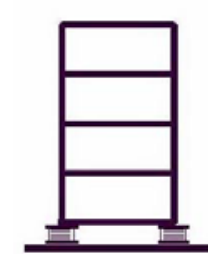

Base isolation

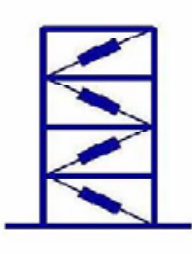

PED

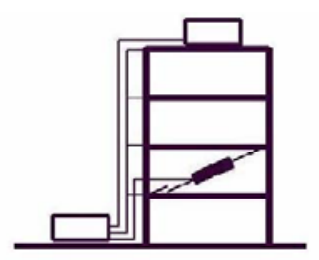

Active control
Fig. 1. Structural protective systems of structure.

\section{FRICTION PENDULUM DAMPER (FPD)}

Friction Pendulum Damper has an initial slip-load $(\mu W)$ and a lateral restoring stiffness $(\mathrm{W} / \mathrm{R})$ with regard to its special geometry same as Friction Pendulum System (FPS) in base isolation, where $W$ is supported weight, $\mu$ is coefficient friction and $R$ is the radius of curvature of concave surface [6]-[9].

Difference between FPD and Pall friction damper is due to lateral restoring stiffness of FPD. This damper can be designed not to slide under weak earthquake or wind load, but it begins to slide during strong earthquakes under a predetermined force. This slide dissipates the input energy to the structure and prevents braces and other structural elements to yield. The special configuration of FPD dampers should be used in chevron and inverted chevron $(\mathrm{V})$ braces. Fig. 2 indicates this special configuration [10]-[12].

\section{MODELING}

Models used in this paper for studying Pall friction and Friction Pendulum Dampers have been adopted from Montgomery and Hall researches, in 1979. They evaluated a 
low-rise steel industrial structure equipped with Pall friction damper by DRAIN-2D program. Fig. 3 shows properties of the low-rise industrial moment frame. All floors are rigid and the structural elements are modeled nonlinearly. In order to observe the effect of lateral restoring stiffness of FPD on the structure, simple braced frame has been modeled [13]-[15].

An 8-story braced structure has been evaluated in addition to the 3-story structure. The 8 -story braced frame has been designed following the requirements of AISC specification and criterions of National seismic code of Iran (2800). Type of soil material is $\Pi$ and structure has been located in a high seismic region. Yield strength $\left(F_{Y}\right)$ and ultimate strength $\left(F_{U}\right)$ are 24000 ton $/ \mathrm{m}^{\wedge} 2$ and 37000 ton $/ \mathrm{m}^{\wedge} 2$.Span length of the bays is 5 meters and height of the stories is 3.2 meters. All floors are rigid and weight of each floor is 45 ton. System of lateral bearing of the 8 -storey braced structure has been designed without damper and 20 percent weaker initially to highlight the role of FPD in reduction of damage and absorbing earthquake energy. 3-storeyand 8-storey braced frames have been shown in Fig. 4 and Fig. 5 respectively.

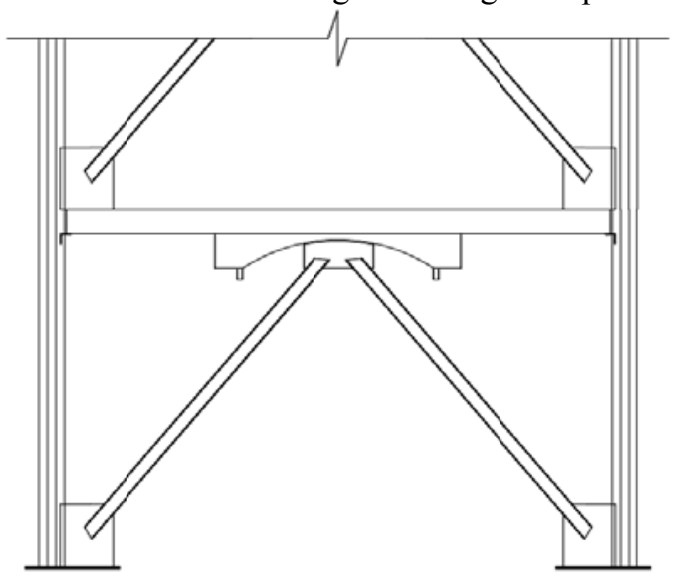

Fig. 2. FPD in chevron braced frame.

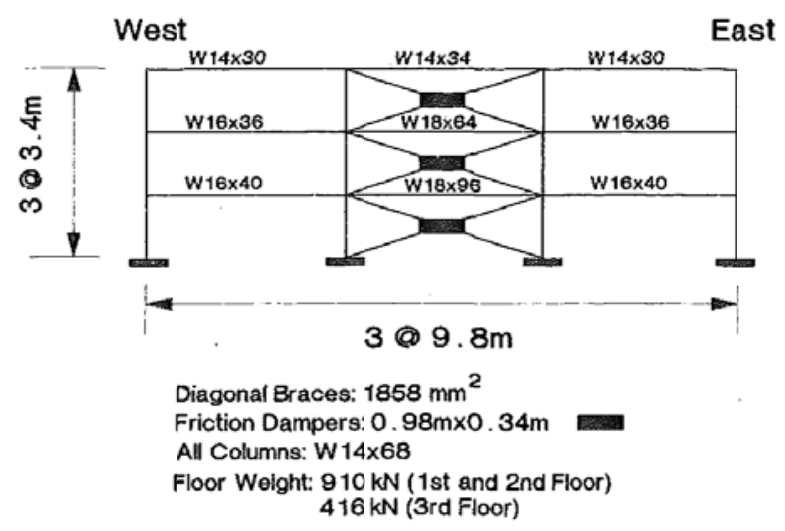

Fig. 3. Low-rise steel industrial structure.

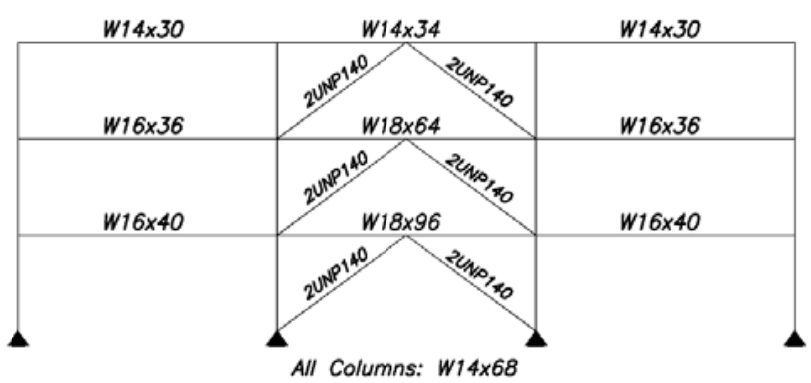

Fig. 4. 3-storey braced frame.

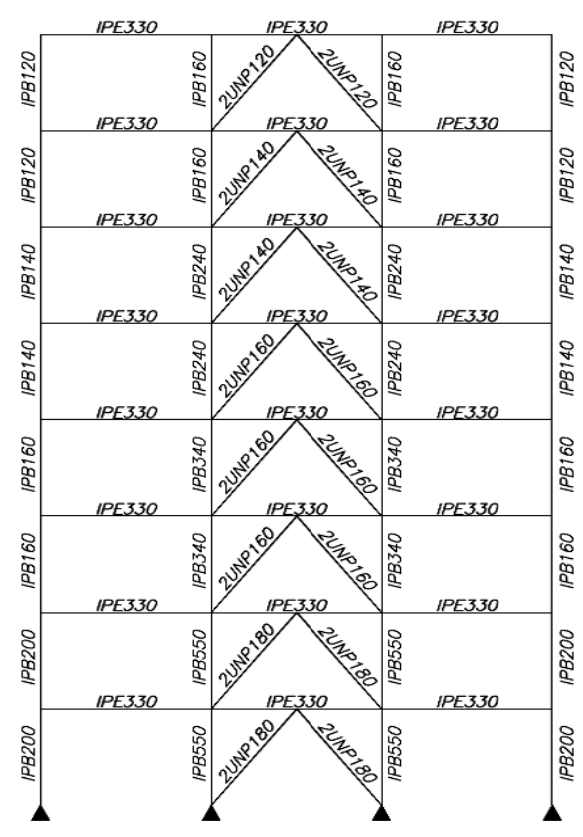

Fig. 5. 8-storey braced frame.

\section{NumericAl RESUlts}

To evaluate the effects of FPD on structural response, nonlinear time history analyses of 3 and 8 story structure with and without FPD and Pall dampers have been conducted under the El Centro and Tabas earthquakes. The two earthquakes have been normalized for maximum ground acceleration of $0.36 \mathrm{~g}$.

The results show that when the structures are not equipped with dampers some braces in both 3 and8-storey are damaged under both earthquakes. However the braces of the frames equipped with FPD are not damaged. This indicates that FPD as a friction damper can dissipate considerable amount of energy.

The main difference of FPD with Pall damper is the restoring force of FPD that can be adjusted by its radius of curvature, R. To conduct the effect of $\mathrm{R}$ on structural response, the structures have been analyzed for different values of $R$ ( 0.5 to $2 \mathrm{~m}$ ) and the results have been compared with the results of Pall damper. The time histories of top floors are shown for different cases in Fig. 6-Fig. 9.

As seen in Fig. 6-Fig. 9, maximum displacement increases when radius of curvature (R) goes up. It is because, lateral restoring stiffness $(\mathrm{W} / \mathrm{R})$ reduces as $\mathrm{R}$ increases. An important point seen in the figures is the residual displacement at the end of earthquake for the structures equipped with Pall friction damper. This residual displacement decreases with reducing $\mathrm{R}$ for structures with FPD damper.

To capture the optimum slip load for Pall and FPD dampers different nonlinear time history analyses have been conducted for 3 and 8-storey frames under different slip-loads and radiuses of curvature. Results are shown in Fig. 10-Fig. 13.

When slip-load in FPD and Pall friction damper increases, maximum top floor lateral displacement reduces and base shear increases. The optimum slip load can be considered as the slip load that its increasing will not cause considerable reduction in displacements. This slip load can be considered 
in the range of $160 \mathrm{kN}$ to $220 \mathrm{kN}$ for 3-storey frame and $120 \mathrm{kN}$ to $180 \mathrm{kN}$ for 8-storey frame.

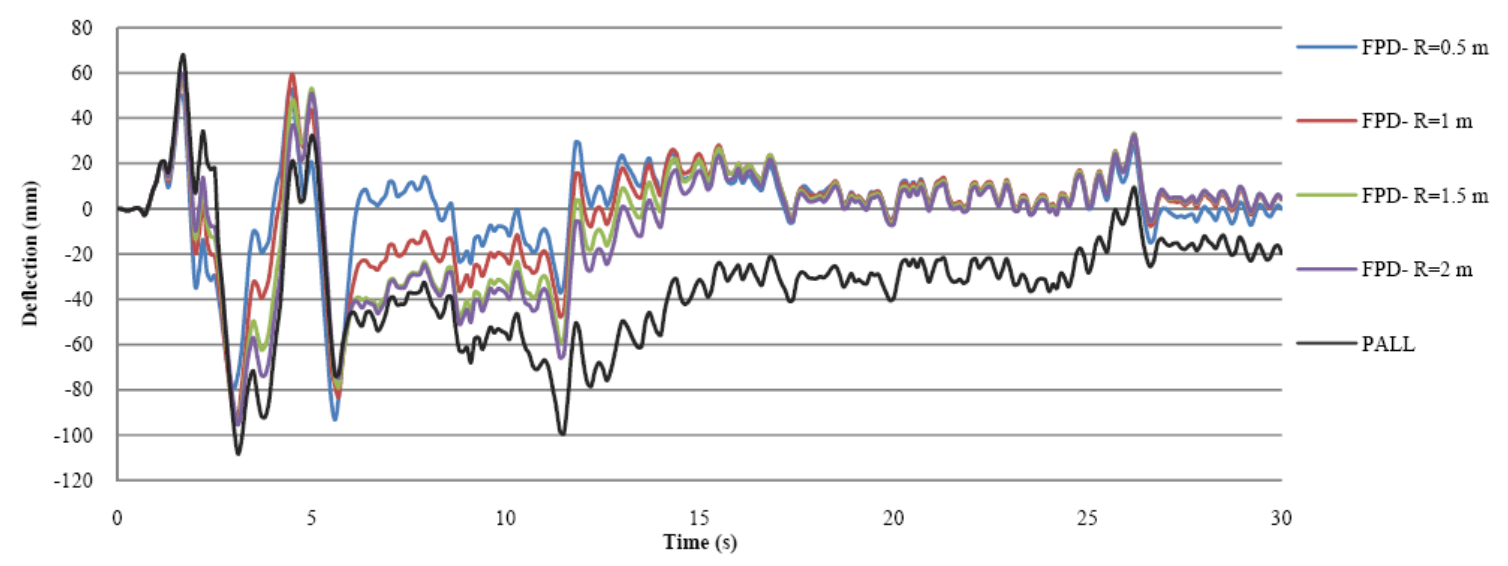

Fig. 6. Top floor lateral deflection for different radiuses of curvature under the $E_{1}$ centro earthquake, Slip-Load $=140 \mathrm{kN}, 3$-storey frame.

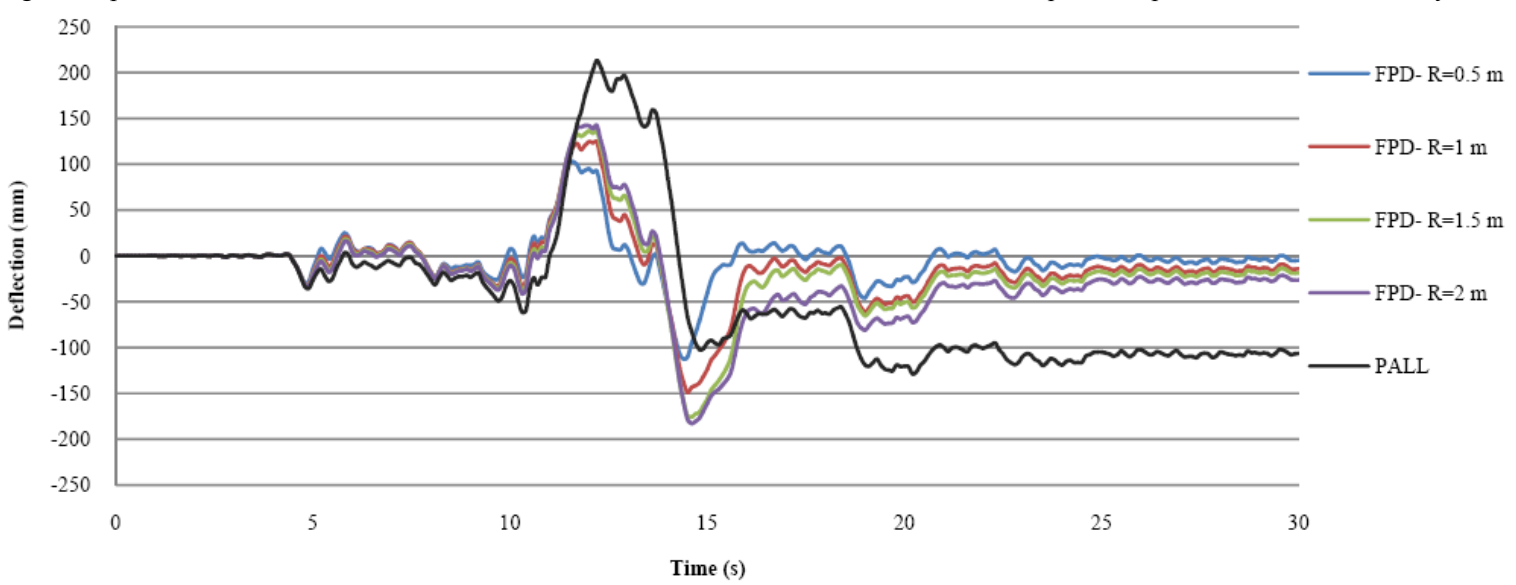

Fig. 8. Top Floor lateral deflection for different radiuses of curvature under the $E_{1}$ centro earthquake, Slip-Load $=100 \mathrm{kN}, 8$-storey frame.

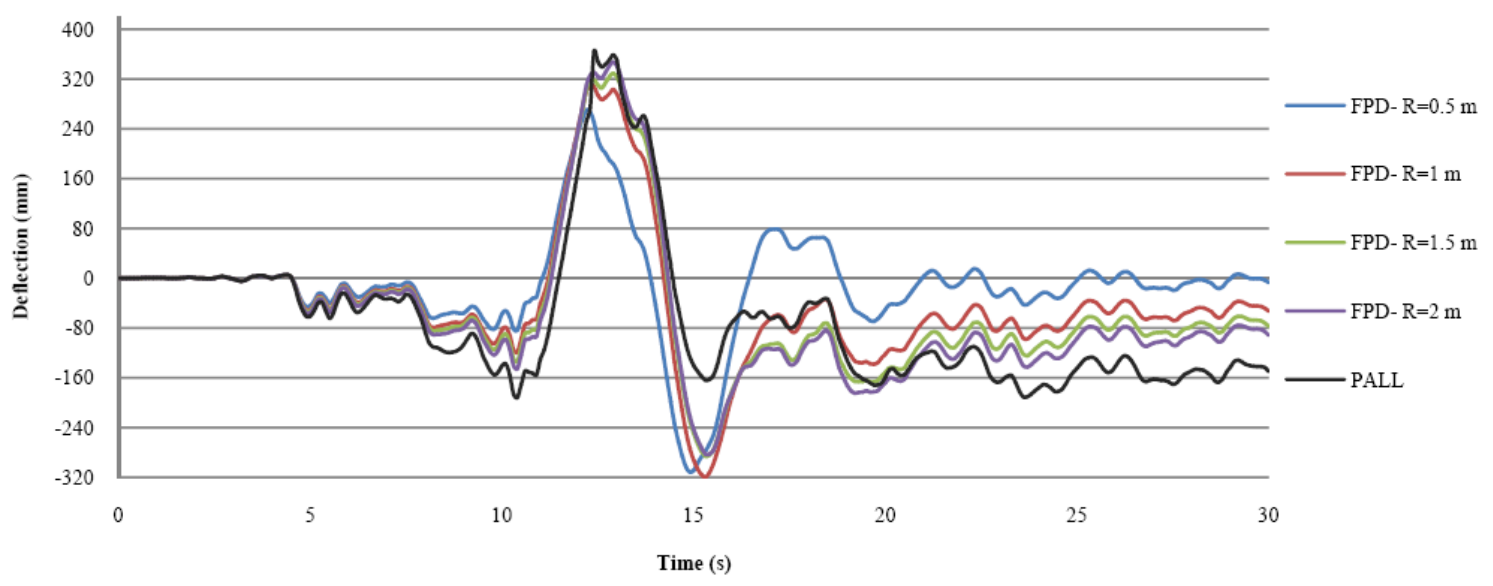

Fig. 9. Top floor deflection for different radiuses of curvature under the tabas earthquake, Slip-Load $=100 \mathrm{kN}, 8$-storey frame.

The results of maximum top floor deflection, maximum base shear and maximum top floor acceleration for the frames with and without FPD and Pall friction dampers for various radiuses of curvature and slip-loads of $200 \mathrm{kN}$ (3-storey) and $160 \mathrm{kN}$ (8-storey) are shown in Fig. 14-Fig. 25.

As seen in the figures, the amounts of maximum base shear and maximum top floor displacement are reduced and increased respectively by increasing R of FPD. Also, amount of maximum top floor acceleration is reduced by increasing $R$ but this reduction is not considerable.

Maximum top floor deflection, maximum base shear and maximum top floor acceleration of 3-storey frame equipped with FPD have been reduced $30 \%, 60 \%$ and $24 \%$ respectively in comparison with the 3-storey frame without damper. Also, Maximum top floor deflection of the frame equipped with FPD has been reduced $15 \%$ more compared to the frame equipped with Pall friction damper while base shear has increased $20 \%$ approximately.

Maximum top floor deflection, maximum base shear and maximum top floor acceleration of 8-storey frame equipped with FPD have been reduced $25 \%, 70 \%$ and $35 \%$ respectively in comparison with the 3 -storey frame without damper. Also, Maximum top floor deflection of the frame equipped with FPD has been reduced $13 \%$ more compared to the frame equipped with Pall friction damper while base shear has increased $20 \%$ approximately. 


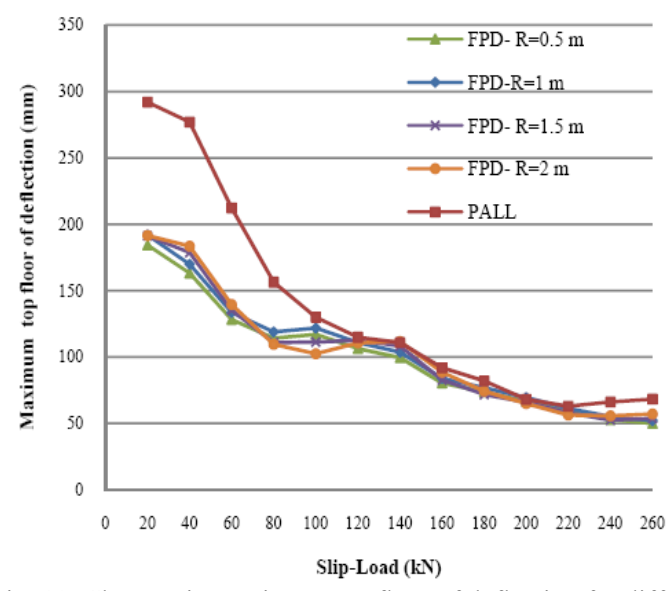

Fig. 10. Changes in maximum top floor of deflection for different slip-loads, $E_{1}$ centro earthquake, 3-storey.

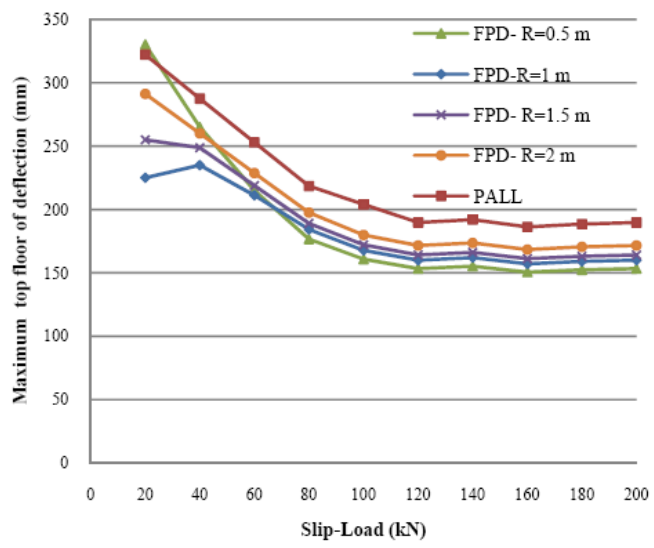

Fig. 11. Changes in maximum top floor of deflection for different slip-loads, $E_{1}$ centro earthquake, 8-storey.

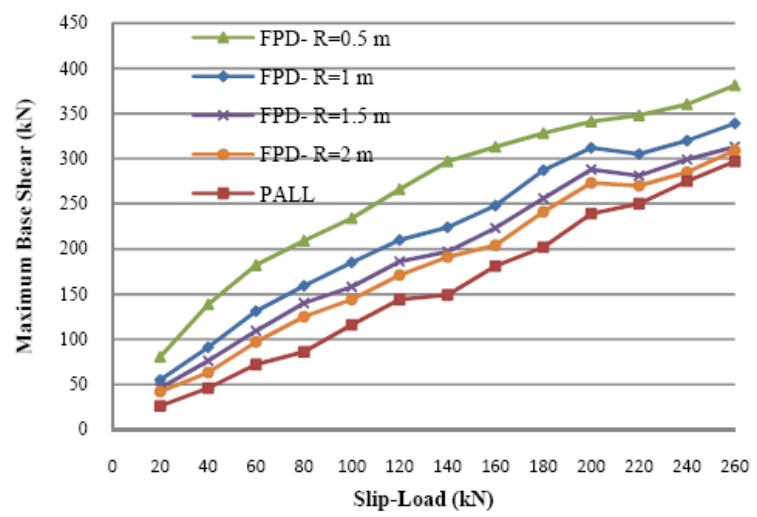

Fig. 12. Changes in maximum base shear for different slip-loads, $E_{1}$ centro earthquake, 3-storey.

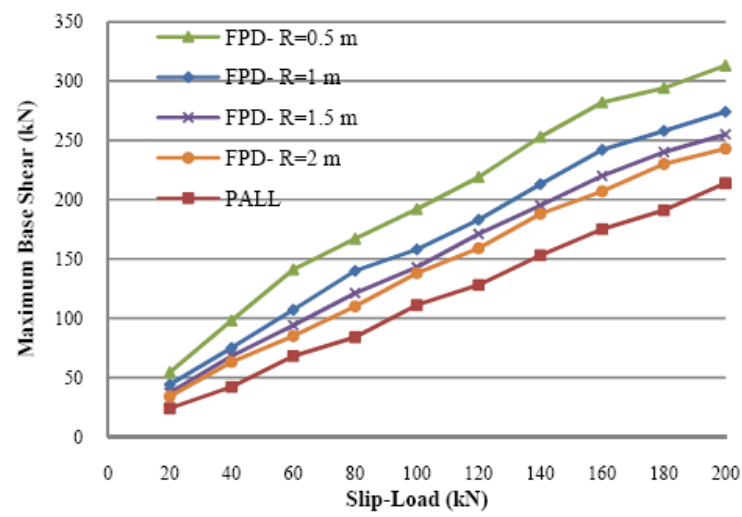

Fig. 13. Changes in maximum base shear for different slip-loads, $E_{1}$ centro earthquake, 8 -storey.

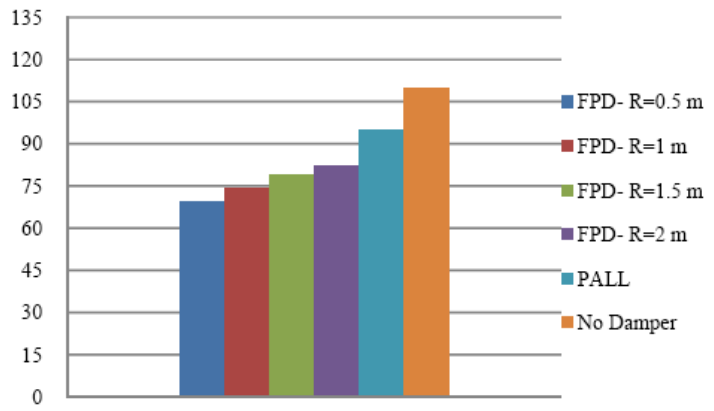

Fig. 14. Maximum top floor deflection (mm), $E_{1}$ centro earthquake, 3 -storey.

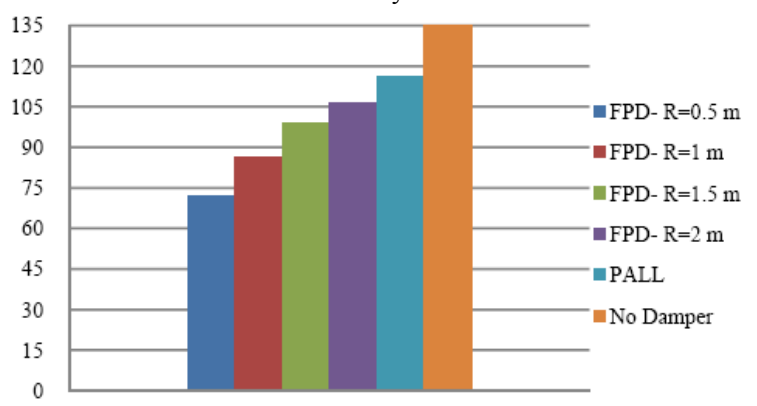

Fig. 15. Maximum top floor deflection (mm), tabas earthquake, 3-storey.

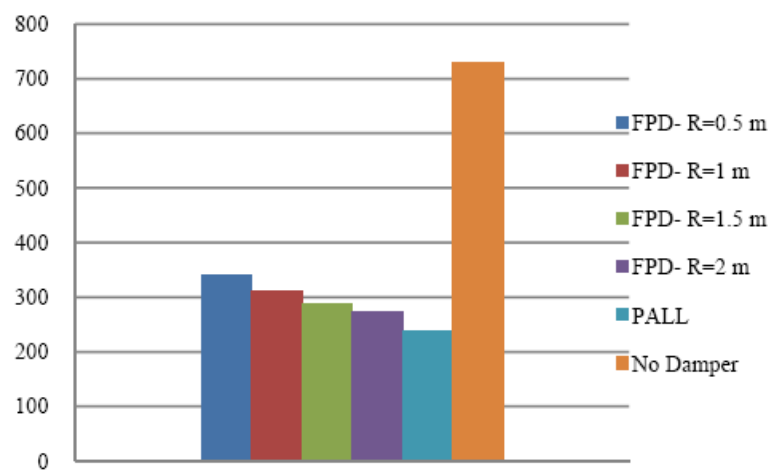

Fig. 16. Maximum Base Shear (kN), $E_{1}$ centro earthquake, 3-storey.

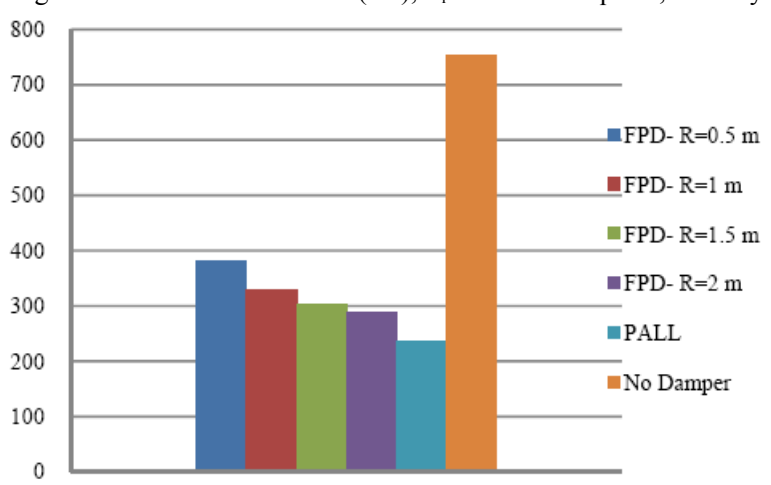

Fig. 17. Maximum base shear $(\mathrm{kN})$, tabas earthquake, 3-storey.

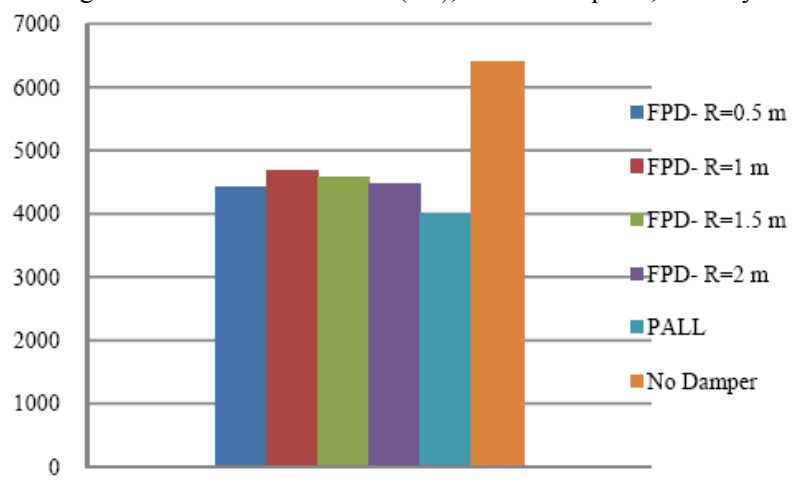

Fig. 18. Maxi mum top floor acceleration $(\mathrm{mm} / \mathrm{s} 2), E_{1}$ centro earthquake, 3-storey. 


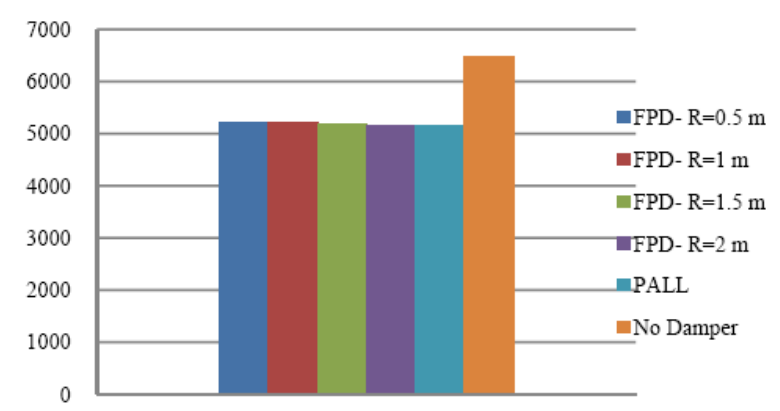

Fig. 19. Maximum top floor acceleration $(\mathrm{mm} / \mathrm{s} 2)$, tabas earthquake, 3-storey.

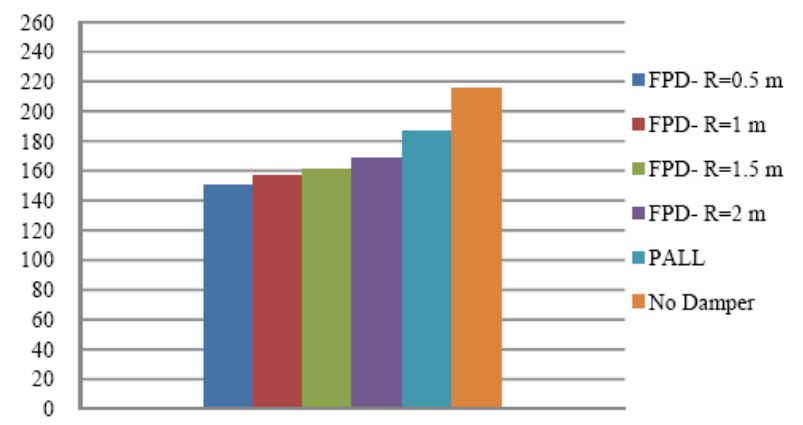

Fig. 20. Maximum top floor deflection ( $\mathrm{mm}), E_{1}$ centro earthquake, 8-storey.

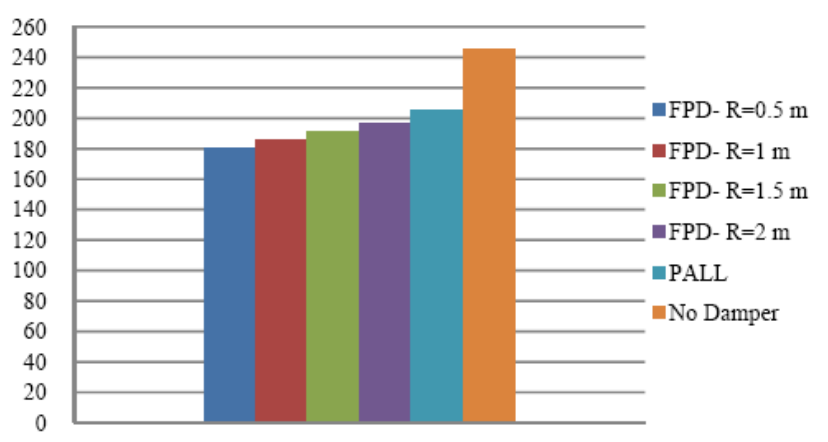

Fig. 21. Maximum top floor deflection (mm), tabas earthquake, 8 -storey.

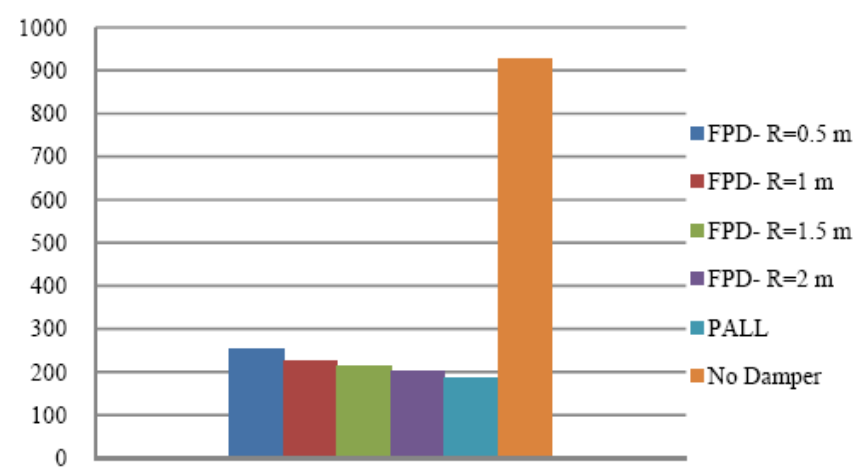

Fig. 22. Maximum base shear $(\mathrm{kN}), E_{1}$ centro 1942 earthquake, 8-storey.

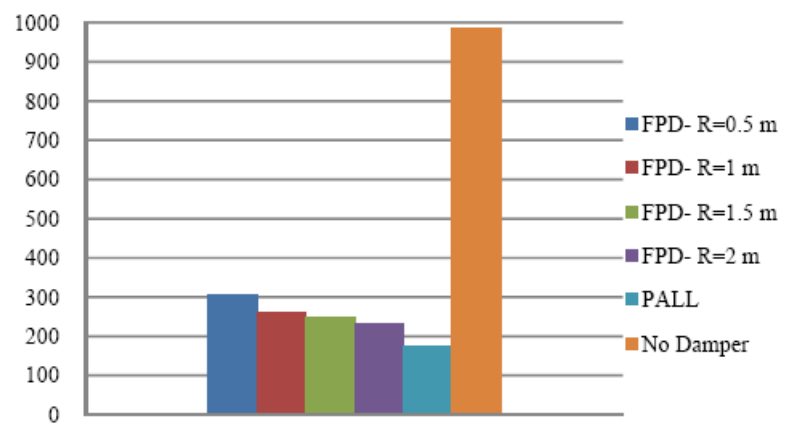

Fig. 23. Maximum base shear (kN), tabas earthquake, 3-storey.

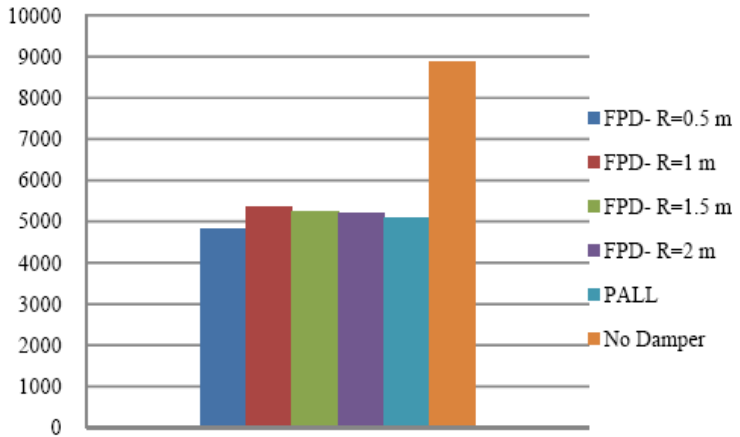

Fig. 24. Maximum top floor acceleration $(\mathrm{mm} / \mathrm{s} 2), E_{1}$ centro 1942 earthquake, 8-storey.

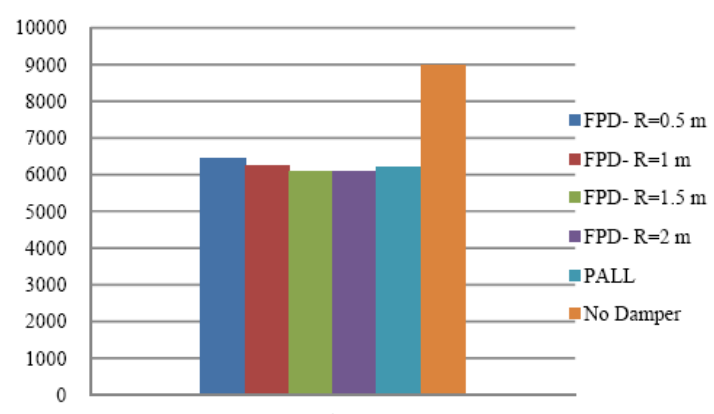

Fig. 25. Maximum top floor acceleration $(\mathrm{mm} / \mathrm{s} 2)$, tabas earthquake, 8-storey.

\section{CONCLUSION}

1) Results of analyses of the frames equipped with FPD indicates that this damper dissipates considerable energy because no braces equipped with FPD yields while some of elements yield in the brace of frames without damper.

2) Some residual deformations are seen in the structure equipped with Pall friction damper at the end of earthquake because this type of damper does not have restoring stiffness while, this residual deformation is greatly reduced in the structures equipped with FPD because of restoring stiffness.

3) Radius of curvature (R) is one of the most important parameters on behavior of FPD. If radius of curvature increases, maximum top floor deflection will increase, while base shear and top floor acceleration will be reduced. When $\mathrm{R}$ increases, behavior of FPD is quite similar to Pall friction damper.

4) Rise in slip-load of FPD and Pall friction damper is accompanied with reduction of maximum lateral top floor deflection and increase in base shear. There is a range of optimum slip-load for each of these dampers that rise in it will not have substantial effect on reduction of deflection.

5) Friction pendulum damper (FPD) through restoring stiffness (W/R) behaves better than Pall friction damper responses in ordinary braced frames and it has been $15 \%$ more effective than Pall in reduction maximum lateral top floor deflection, while base shear has increase quite $20 \%$ in FPD against Pall for different radiuses of curvature.

\section{REFERENCES}

[1] Uniform Building Code (UBC). [Online]. Available: http://www. en.wikipedia.org/wiki/Uniform_Building_Code. 
[2] P. Mahmoodi and L.E. Robertson, "Performance of viscoelastic dampers in world trade center towers," Dynamic of Structures, Sessions at Structural Congres, pp. 632-624, 1987.

[3] A. S. Whittaker, "Seismic rehabilitation using supplemental damping system," EQ. Eng. Research at Berkeley, no.430, 1996.

[4] T. T. Soong and G. F. Dargush, Passive Energy Dissipation Systems in Structural Engineering, 1997.

[5] T. T. Soongand and M. C. Constontinou, Passive and Active Vibration Control in Civil Engineering, 1994

[6] V. A. Zayas, S. S. Low, and S. A. Mahin, "Seismic isolation uses the friction pendulum system," in Proc. the 10th International Conference on Structural Mechanics in Reactor Technology, Anaheim, California, vol. 6, no. 2, 1989.

[7] V. A. Zayas, S. S. Low, and S. A. Mahin, "The FPS earthquake resisting system," Earthquake Engineering Research Center, University of California, Berkeley, p. 90, 1987.

[8] M. Garevski and M. Jovanovic, "Influence of friction pendulum system on the response of base isolated structures," in Proc. 14th World Conference on Earthquake Engineering, Beijing, China, 2008.

[9] A. S. Mokha, M. C. Constantinou, A. M. Reinhorn, and V. A. Zayas, "Experimental study of friction pendulum isolation system,"Journal of Structural Engineering, vol. 117, no. 4, 1991.

[10] Earthquake Protection Systems, "Technical Characteristics of Friction Pendulum Bearings," 451 Azuar Drive, Bldg. 759, Mare Island, Vallejo, California 94592, 2003.

[11] A.S. Pall and C. Marsh, "Response of friction damped braced frames," Journal of Structural Division, ASCE, 1982.

[12] A. Pall and R. T. Pall, "Performance-based design using pall friction dampers an economical design solution," in Proc. 13th World Conference on Earthquake Engineering, Vancouver, Canada. 2004.

[13] A. Filiatrault and S. Cherry, "Efficient numerical modeling for seismic design of friction damped braced steel plane frames," Canadian Journal of Civil Engineering, vol. 16, no. 3, pp. 211-218, 1988.

[14] A. Filiatraultand and S. Cherry, "Comparative performance of friction damped systems and base isolation systemsfor earthquake retrofit and aseismic design," Earthquake Engineering and Struct. Dynamics, vol. 16, no. 3, pp. 389-416, 1988.

[15] A. Filiatrault and S. Cherry, "Performance evaluation of friction damped braced steel frames under simulated earthquake loads," Earthquake Spectra, vol. 3, no. 1, pp. 57-78, 1987.

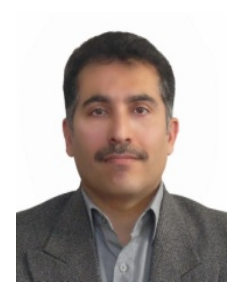

S. M. Zahrai was born in Tehran, Iran in 1964 . He received his B.Sc. in civil engineering from Tehran Polytechnic in 1987, his M.Sc. instructural engineering from the Univ. of Tehran in 1990 and his Ph.D. in structural engineering from the Univ. of Ottawa in 1997.

He has been a professor at the School of Civil Eng., the University of Tehran since 1999. He has authored many publications including 10 books, more than 200 journal and conference papers, so far supervised about 100 theses and research projects, managed and directed lots of large steel and concrete building tower or bridge projects in design and construction phases, served a few conferences as the chairman, and many international journals as member of editorial board or reviewer.

S. M. Zahrai has been also a member of many scientific societies and innovation advisory committees in Iran, awarded a few times for teaching or research and uniquely recognized for about 300 workshops and educational sessions held on different aspects of seismic design, retrofit and construction of steel and concrete building and bridge structures.

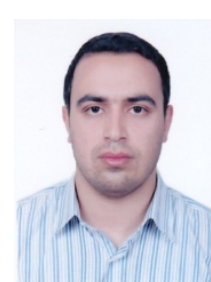

Masoud Bozorgvar was born in Mashhad in Iran in 1986. He received his B.Sc. degree in civil engineering from the Islamic Azad University of Mashhad, Mashhad, Iran in 2008 and his M.Sc. degree in structural engineering from the Ferdowsi University of Mashhad, Mashhad, Iran in 2012. He is a PhD student at Islamic Azad university of Arak, Arak, Iran. He has been involved in design and construction of residential buildings. He was responsible for design and construction of structures. His research interests are seismic analyses and structural dynamics.

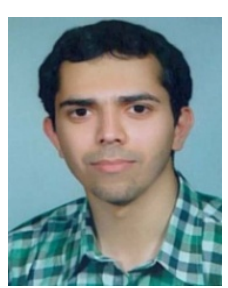

Mahmood Bozorgvar was born in Mashhad in Iran in 1985. He received his B.Sc. degree in civil engineering from the Iran University of Science and Technology, Tehran, Iran in 2008 and his M.S. degree in structural engineering from the Ferdowsi University of Mashhad, Mashhad, Iran in 2011.

$\mathrm{He}$ has been involved in construction of tall buildings. Also, when he was passing his military service, he was responsible for design and construction of industrial structures. He has studied blast loadings on reinforced concrete structures to compare behavior of the structures to blast and earthquake with each other and has paper published on $9^{\text {th }}$ International Congress on Civil Engineering, May8-10,2012, Isfahan University of Technology(IUT), Isfahan, Iran. His research interests are finite element method and structural dynamics. 